\title{
Mass Hair Cover
}

National Cancer Institute

\section{Source}

National Cancer Institute. Mass Hair Cover. NCI Thesaurus. Code C90421.

A description of the quantity or quality of the hair or fur covering a mass. 